\title{
A Hospitalidade e Cordialidade Brasileira: o Brasil percebido por estrangeiros
}

\section{The Hospitality and Courtesy in Brazil: the country perceived by foreigners}

\author{
Carlyle Tadeu Falcão de Oliveira ${ }^{1}$ \\ Paulo Emílio Matos Martins ${ }^{2}$
}

\begin{abstract}
Resumo
O tema central deste ensaio é o traço cultural de 'cordialidade' do homem brasileiro, na acepção de Sérgio Buarque de Holanda, como sendo uma das principais motivações para os turistas estrangeiros viajarem ao Brasil. A partir de uma visão panorâmica do mercado turístico mundial e da constatação da incipiente participação do país no mesmo, este ensaio busca uma explicação desse fator motivador através da teoria do "homem cordial" de Holanda, também sinalizada nas obras de Gilberto Freyre, José Carlos Reis, e em tantos outros intérpretes do Brasil. Finalmente, este artigo sugere que essa "hospitalidade" referida por nossos visitantes estrangeiros deriva da natureza "cordial" antes aludida, podendo assim constituir-se em importante fator diferencial na elaboração de uma política para o setor.
\end{abstract}

Palavras-chave: hospitalidade; cordialidade; personalismo; herança ibérica; turismo.

\begin{abstract}
The central theme of this essay is the cultural trait of 'cordiality' present on brazilian, according to Sergio Buarque de Holanda's sense, as one of the main motivations for foreign tourists travel to Brazil. Using a panoramic view of the world tourist market and the low participation of the country in it, this study seeks an explanation about this motivating factor through the theory of Holland's "cordial man", also mentioned in Gilberto Freyre's, Jose Carlos Reis's works and in many other interpreters of Brazil. Finally, this article suggests that such "hospitality", referred by foreign visitors, comes from the cordiality mentioned before and it may well be a differentiation factor for policy development to the tourism sector.
\end{abstract}

Keywords: hospitality; cordiality; personalism; Iberian heritage; tourism.

\footnotetext{
1 Mestre em Administração Pública (FGV-EBAPE), MBA em Gestão Empresarial (FGV-Management), Especialista em Planejamento e Gestão em Turismo Ambiental e Cultural (UNIRONDON), Engenheiro Civil (UGF), Pesquisador do Núcleo de Turismo da FGV-EBAPE, Coordenador do Observatório de Inovação do Turismo (FVG-EBAPE). E-mail: carlyle.falcao@fgv.br

2 Doutor em Administração de Empresas (EAESP-FGV), Mestre em Administração Pública (EBAP-FGV), Engenheiro Mecânico (UFPA), Professor Titular e Coordenador do Programa de Estudos de Administração Brasileira (EBAPE-FGV).E-mail: paulo.martins@fgv.br
} 


\section{Introdução}

A Organização Mundial do Turismo (OMT), órgão das Nações Unidas (ONU), recomendou às nações membros que o turismo em 2007 fosse consolidado como agente chave na luta contra a pobreza e usado como uma ferramenta fundamental para o desenvolvimento sustentável (OMT, 2007). Seu secretário geral, Francesco Frangialli (2007), informa que nos países mais pobres do mundo o turismo é o setor produtivo responsável pela maior receita de exportação e o que mais recebe investimento estrangeiro direto. A taxa de crescimento do turismo nesses países é duas vezes maior que o da industrialização, não existindo nos mesmos outro setor que gere mais riqueza e empregos do que a atividade turística, pois esta envolve uma enorme cadeia produtiva englobando lazer e negócios produzindo bens e serviços. Nos países industrializados este setor representa de 3 a $5 \%$ do Produto Interno Bruto (PIB) e nos em processo de desenvolvimento chega a 30 \% do PIB. Em 2003 as receitas internacionais do turismo representaram $6 \%$ de todos os bens e serviços exportados no mundo inteiro e perto de $30 \%$ levando-se em conta apenas o setor de serviços, haja vista ser o turismo, atividade do terceiro setor.

Em 2006 ocorreram 842 milhões de chegadas internacionais (indicador usual para a mensuração do fluxo turístico internacional) e um crescimento de 4,5\%, estabelecendo assim um novo recorde para a indústria turística, mesmo levando em conta recentes ameaças inibidoras dessa atividade como, por exemplo, o crescimento do terrorismo internacional, a elevação do preço do petróleo e a gripe aviária. É importante ressaltar que as estatísticas aqui apresentadas não consideram o movimento doméstico de turistas, isto é, o fluxo dos turistas dentro de seu próprio país. (ORGANIZAÇÃO MUNDIAL DO TURISMO, 2007).

Em 2005 o Brasil recebeu 5,4 milhões de turistas estrangeiros, participando com 0,67\% do movimento total de turistas no mundo. Muito pouco se comparado aos vizinhos americanos México (21,9 milhões) e EUA (49,4 milhões). Esses turistas deixaram nos países que visitaram, milhões de dólares, respectivamente: 3,9 (Brasil); 11,8 (México) e 81,7 (EUA). As ilhas caribenhas, cujas economias baseiam-se fortemente na atividade turística, faturaram nesse mesmo ano, 20,4 milhões em moeda americana.

O litoral brasileiro, com oito mil quilômetros de extensão, possui belíssimas praias em meio a dunas, Mata Atlântica, lagoas, montanhas, ilhas paradisíacas e natureza cênica. Dos 850 milhões de hectares do território nacional, aproximadamente 550 milhões são cobertos por florestas nativas, dois terços são formados pela floresta amazônica e o restante pelo Cerrado, Caatinga, Mata Atlântica e seus ecossistemas associados. A superfície de florestas do Brasil 
equivale a $14,5 \%$ da superfície florestal mundial (EMBRAPA, 2004) sendo o país com a maior biodiversidade vegetal do planeta, com mais de 55 mil espécies vegetais num total equivalente a quase $25 \%$ de todas as espécies de plantas existentes. O Pantanal Matogrossense é, segundo a UNESCO (1996), uma das mais exuberantes e diversificadas reservas naturais do planeta integrando-se ao acervo dos patrimônios naturais da humanidade. A cultura brasileira é rica em história, costumes, culinária, festas populares, folclore e é tão diversificada como a etnia de seu povo e suas raízes culturais.

Que fatores diferenciadores mereceriam mais atenção por parte dos formuladores das políticas públicas para o setor melhorar a participação do Brasil no mercado internacional?

Este artigo tem como objetivo explicar o traço cultural de "cordialidade", presente nos brasileiros, como possível fator de diferenciação para o turismo brasileiro no plano internacional.

Partindo da análise dos dados de uma pesquisa da EMBRATUR/FIPE realizada em 2004 e 2005, que apontava para a resposta "a hospitalidade e o gosto pelo Brasil" como o motivo que mais favorecia para viajar ao país, surgiu o questionamento: o que faz do brasileiro uma "pessoa hospitaleira"?

Pesquisando as obras de Gilberto Freire (2005), Sérgio Buarque de Holanda (1995) e José Carlos Reis (2005), construiu-se um arcabouço da formação racial brasileira. É mostrada a miscigenação da cultura ibérica com a negra e a indígena. A ruralidade do país colonial juntamente com esse amálgama racial brasileiro fornece os contornos de um dos traços mais marcantes da personalidade brasileira: a cordialidade.

Esse aspecto cultural brasileiro é discutido de maneira dialógica. Ressaltam-se suas características que favorecem o lado hospitaleiro do brasileiro de um lado e por outro, uma das suas mazelas, o personalismo. Esse personalismo é abordado por meio de suas manifestações, como a concentração de poder, o patrimonialismo e na sua manifestação mais evidente: o "jeitinho brasileiro".

A civilidade é apresentada no trabalho como conseqüência do processo de urbanização ocorrida nos países mais desenvolvidos, em que a impessoalidade suplantou as relações mais afetivas e familiares. O "homem civilizado" e impessoal é colocado em oposição ao "homem cordial" e sentimental. 
Consideramos que os resultados das pesquisas aqui relatadas apontam para um atrativo turístico que não diz respeito a nenhuma de ordem natural ou cultural material do Brasil, mas um bem imaterial inerente ao povo brasileiro: a hospitalidade.

\section{A Hospitalidade Brasileira e o "Homem Cordial"}

\subsection{A hospitalidade brasileira}

Numa pesquisa de mercado com turistas estrangeiros, nos principais terminais de passageiros do país, realizada entre 2004 e 2005 pela Fundação Instituto de Pesquisas Econômicas -FIPEe o Instituto Brasileiro de Turismo - EMBRATUR/ Ministério do Turismo, indagou-se sobre o motivo principal que favorecia viajar para o Brasil. A resposta da maioria, num universo de onze alternativas (entre belezas naturais, clima, cultura, preço e outros) foi: "a hospitalidade/gosto pelo Brasil”.

O que significaria "hospitalidade/gosto pelo Brasil" na visão desses visitantes estrangeiros? Dito de outro modo, o que faz do brasileiro uma "gente hospitaleira"?

Vinícius Lages, gerente da Unidade de Desenvolvimento Setorial do Serviço de Apoio a Pequena e Média Empresa - SEBRAE vem buscando identificar características da cultura brasileira que possam orientar estratégias inovadoras e que agreguem valor na produção de bens e serviços no país, inclusive no setor de turismo, destaca: “Um dos traços que aparecem em nossas pesquisas é que os brasileiros são reconhecidos como um povo irmão, um povo primo de quase todo mundo, porque tivemos aqui diversas correntes migratórias". (MOVIMENTO BRASIL DE TURISMO E CULTURA, 2006, p.1).

Não se pode conceber que hospitalidade seja apenas a atividade turística de hospedar o viajante, ou a relação comercial de oferecer abrigo, alimentação em troca de pagamento. Há mais do que isso, o ato de receber pressupõe uma troca de valores entre visitantes e visitados. Os turistas não ficam restritos aos lugares de hospedagem ou de visitação, circulam pela comunidade receptora interagindo com a população local. Para Praxedes (2004, p.2):

A hospitalidade é uma forma de relação humana baseada na ação recíproca entre visitantes e anfitriões. Sempre que os humanos se relacionam, mesmo para a realização de atividades práticas ligadas a receber ou visitar alguém ou um local, o relacionamento depende dos valores daqueles que estão interagindo, ou seja, depende dos princípios que orientam as condutas dos envolvidos na relação. 
Ainda de acordo com aquele autor, hospitalidade é ato de receber bem o visitante, fornecerlhe o conforto, bem estar e segurança que normalmente seriam encontrados em sua casa. Seria impossível conceber um ambiente hospitaleiro sem que toda a localidade receptora participasse conjuntamente nesse sentido. $\mathrm{Ou}$, em suas próprias palavras: "Hospitalidade é a generosidade de um agrupamento humano, seja uma comunidade, etnia, cidade, nação, estado ou país. É a ternura da gente de um lugar em relação ao estrangeiro e os seus mistérios [...]". (PRAXEDES, 2004, p.5)

\subsection{A "gente brasileira"}

Foi a solidão da grandeza do território brasileiro e a necessidade dos colonos de constituírem família que aproximou o colonizador branco das índias e das escravas negras numa fantástica miscigenação de raças. Assim, esse amálgama racial adentrou o sertão brasileiro, dividiu propriedades entre brancos, pretos, índios e seus filhos (legítimos e bastardos). Foi também essa miscigenação racial que mais contribuiu para a democratização do Brasil, como lembra José Carlos Reis, com base no clássico Casa Grande Senzala de Gilberto Freyre:

Aqui, houve o encontro, a intercomunicação e a fusão harmoniosa de tradições diversas de cultura. A cultura européia se pôs em contato com a indígena, contato amaciado pelo óleo lubrificante da mediação africana. A invasão, escravização e estupro de negras e índias pelos portugueses não foi seca: foram lubrificados pela doçura africana, pela forte excitação da mulher indígena, pelos presentes e novidades dos brancos, pela adaptabilidade, aclimatabilidade, miscibilidade, plasticidade e falta de orgulho de raça do português (REIS, 2005, p. 68).

Seguindo com Gilberto Freyre, Reis (2005) destaca a convivência muito próxima que existiu no Brasil colonial rural entre as casas grandes - onde os senhores do açúcar ou do café reinavam absolutos - e as senzalas - dos escravos, onde, distantes do poder do Estado, os primeiros eram soberanos. Essa convivência incluía os filhos de senhores e escravos, seus companheiros de brincadeiras de infância, as mulheres negras, suas iniciadoras sexuais as quais, em muitas ocasiões, forneciam o aconchego do colo durante a infância. Foi este ambiente da casa grande que Freyre define como o terraço "de onde com a vista o fazendeiro abarcava todo o organismo da vida rural, o terraço hospitaleiro, patriarcal e bom". (REIS, 2005, p.65),

De acordo com Freyre (2005), a sociedade brasileira era uma das mais democráticas, flexíveis e plásticas. Os antagonismos de senhores e escravos, de brancos, índios e pretos, foram harmonizados pela miscigenação, pela liberdade do ir e vir num espaço geográfico sem 
limites e pela tolerância moral. Reinava uma democracia social e o regime imperial era uma combinação de democracia e monarquia. Este era o cenário do Brasil colônia, uma multiplicidade de casas grandes e senzalas ou de repúblicas-familiares onde o senhor autoritário mantinha poder absoluto sobre a família e escravos, mas também legitimado por relações afetivas e de fidelidade recíprocas.

Essa tolerância racial é que abria o espírito dos homens para a fraternidade e um bem estar social que caracteriza o lado feliz do brasileiro, um traço marcante de sua personalidade, a crença na existência de um paraíso terrestre, de uma democracia social e de uma "felicidade brasileira" (REIS. p. 80). Era o poder familiar, patriarcal que governava, também, a naçãocolônia brasileira.

"Um povo irmão, afetivo, espontâneo, cordial, autêntico, alegre, generoso, festeiro e barulhento". Essa definição foi dada por muitos turistas estrangeiros que visitam o Brasil e debatidas durante o $1^{\circ}$ Colóquio sobre Cultura Brasileira da Hospitalidade, iniciativa do Movimento Brasil de Turismo e Cultura, realizado em junho de 2006 durante a segunda edição do Salão do Turismo em São Paulo. Empresários do setor de hotelaria estrangeira, que participaram do colóquio, relataram que a cordialidade e o calor humano estariam no jeito brasileiro de ser e esses seriam nosso grande diferencial receptivo. Freyre atribui tais traços comportamentais às relações fraternas e cordiais entre as raças de nossa formação:

Os brasileiros se amam como irmãos, mesmo se são tão diferentes. Há preconceitos, mas não há apartheid. Reina entre os brasileiros um forte espírito de fraternidade. As relações entre negros e brancos sempre foram cordiais, e a solução brasileira para as relações raciais foi a mais inteligente, promissora e humana. [...] Há miséria, doença, tristeza, opressão. Mas não se pode deixar de falar de democracia social. (REIS, 2005, p.80)

Dentro desse ambiente fraterno e hospitaleiro do período colonial, lembrado por Reis, e os depoimentos do $1^{\mathrm{o}}$ Colóquio sobre Cultura Brasileira da Hospitalidade, nota-se que a cordialidade está presente.

Da leitura de Raízes do Brasil de Sérgio Buarque de Holanda, Reis ressalta a cordialidade como herança colonial do domínio patriarcal rural. Dizia que na vida colonial rural prevalecia a família e o poder pátrio, que propagavam para toda a sociedade os sentimentos próprios da vida doméstica. Por fim, a "vida pública, social e política eram marcadas pela família rural colonial'. (REIS, 2005, p. 128) 
A colonização portuguesa foi tipicamente rural, manteve o Brasil imerso num feudalismo tardio que se prolongou pelo início da modernidade enquanto a Europa rompia com esse arcaico modelo econômico e entrava no mercantilismo. Havia no Brasil escravos e senhores, inexistia uma classe intermediária expressiva, uma burguesia capaz de cobrar mudanças, pelas quais fazia a Europa ferver em revoluções e inovações. Prevalecia a vida doméstica e familiar e as relações sociais simples e diretas, mais íntimas e cordiais (AVELINO, 1990). A cordialidade foi realçada por Sérgio Buarque de Holanda como uma das características mais marcantes do caráter brasileiro e reconhecida por todos aqueles que nos visitam, compreendendo nela a hospitalidade, a generosidade e a intimidade:

[...] a contribuição brasileira para a civilização será a de cordialidade - daremos ao mundo o "homem cordial". A lhaneza no trato, a hospitalidade, a generosidade, virtudes tão gabadas por estrangeiros que nos visitam, representam, com efeito, um traço definido do caráter do brasileiro [...] (HOLANDA, 1995, p.146)

\subsection{Hospitalidade e cordialidade}

Seriam as idéias de cordialidade e hospitalidade interdependentes?

Haveria um ambiente hospitaleiro isento de cordialidade?

Quando turistas estrangeiros apontam para o fator "hospitalidade/gosto pelo Brasil" como o que mais lhes atrai no país, estariam eles referindo-se ao jeito brasileiro de ser, informal, descontraído, amigável, emotivo, ou apenas à hospitalidade formal oferecida em caráter profissional pelos meios de hospedagem? A cordialidade é um "padrão de convívio humano" que tem como modelo as relações privadas características do meio rural e patriarcal; é a expressão legítima de "um fundo emotivo extremamente rico e transbordante" (HOLANDA ap. ESTEVES, 1998, p.2). O homem cordial é fruto da nossa herança ibérica segundo Holanda (1995), na qual se destacam a "cultura da personalidade", a "autonomia do homem", a "frouxidão das estruturas sociais" e a "falta de hierarquia organizada". Avelino (1990, p.8) complementa o pensamento de Holanda:

A cordialidade é o resultado direto da materialização da cultura da personalidade na colônia; é somente com o processo de urbanização que a cordialidade, junto com influência ibérica, começa a enfraquecer-se. Herança ibérica, ruralismo e cordialidade são coisas que andam juntas. 
O brasileiro é herdeiro da colonização ibérica, segundo Sérgio Buarque de Holanda (1995), moldada ao calor dos trópicos e na vastidão do território brasileiro. A receptividade brasileira aos povos estrangeiros está ligada a uma formação multirracial e cultural que nos torna receptivo e hospitaleiro às demais raças e culturas.

Holanda (1995) mostra que a cordialidade é tão forte na sociedade brasileira que penetrou nas relações comerciais, marcadas pela racionalidade e impessoalidade. A forma de convívio entre brasileiros, se dá com intimidade, é percebida com dificuldade por estrangeiros, conforme relato de comerciantes forasteiros, que diziam precisar fazer amizades para conquistar fregueses. É a cordialidade que torna as relações sociais mais íntimas e conduz a informalidade, segundo Holanda. Prova disso está na utilização acentuada do nome de batismo para tratamento entre pessoas, ao qual, muitas vezes, se acrescenta o sufixo diminutivo "inho", de modo a se estabelecer maior familiaridade e intimidade entre elas.

Por outro lado, para Holanda (1995), o personalismo está diretamente ligado à cordialidade. Esse personalismo combinado com a concentração de poder resultaria no paternalismo - a personificação das relações entre chefe e subordinado. Barros, Prates e Diniz (1991, p.8) relatam que "o brasileiro espera por ou acredita mais em um comando forte e centralizado do que em um poder difuso e não personificado" - tal qual o poder pátrio da família colonial que se faz ainda presente na nossa sociedade.

A partir desse ponto destacam-se as características negativas da cordialidade presentes no ambiente organizacional, já que este reflete a sociedade onde está inserido. Em pesquisas realizadas pelos citados autores (BARROS, PRATES e DINIZ, 1991) em empresas de grande porte da região sudeste do país, constatou-se a presença do personalismo e da concentração de poder. Tomando como base essas duas mazelas organizacionais os autores partem para a identificação de outras também detectadas na mesma pesquisa.

O quadro familiar torna-se, assim, tão poderoso e exigente, que sua sombra persegue os indivíduos mesmo fora dos recintos doméstico. "[...] a nostalgia dessa organização compacta, única e intransferivel, onde prevalecem necessariamente as preferências fundadas em laços afetivos, não podia deixar de marcar nossa sociedade, nossa vida pública, todas nossas atividades." (HOLANDA, 1995, p.82)

Esse personalismo e a concentração do poder, segundo Barros, Prates e Diniz (1991), ainda seria origem do patrimonialismo, da dependência, da participação como espectador, do 
controle das incertezas, da lealdade às pessoas, da fuga de conflitos, da impunidade e criatividade, todas presentes em maior o menor grau nas organizações brasileiras.

Uma história de dominadores e dominados nas quais se evidenciam as relações paternalistas carregadas de afetividades e cordialidades é apresentada sucintamente por Alcadipani e Motta (1999). Eles destacam que os europeus casavam com índias para utilizarem o costume indígena de adotarem o marido como cunhado da tribo e assim trabalharem no extrativismo da tinta do pau-brasil. No período colonial os senhores de engenho e fazendeiros exerciam seu poder absoluto sobre a família e escravos, sendo suas decisões orientadas por sentimentos afetivos que reforçavam e ao mesmo tempo amenizavam sua autoridade. Os coronéis, no período republicano, dominavam através do afeto e violência a sociedade da época. Esses autores destacam "as relações paternalistas, a indole de fundo emotivo (sentimentalista), marcada por relações de amor e ódio que se colocam sobre as atitudes econômico-racionais, como uma característica cultural brasileira". (ALCADIPANI E MOTTA ,1999, p.8)

O tão conhecido "jeitinho brasileiro" - forma encontrada para se contornar obstáculos e dobrar a dureza da burocracia - tem também sua faceta de cordialidade. A burocracia é, segundo Weber (1963, p.344), "uma estrutura de dominação legal caracterizada pela existência de áreas de jurisdição fixas e oficiais, ordenadas de acordo com regulamentos". O modelo burocrático weberiano define-se então como tendo as características de: "racionalidade funcional, hierarquia, impessoalidade e distinção entre o domínio público e privado".

É por meio de relações cordiais que o "jeitinho" aparece para quebrar a impessoalidade da burocracia e atingir determinados fins pessoais. Utiliza-se o "jeitinho" para "driblar" hierarquias e desfazer a distinção do público pelo privado quando necessário. A reação da burocracia ao "jeitinho brasileiro" foi justamente o recrudescimento das normas fazendo aparecer a questão do formalismo que, segundo os autores, seria a diferenciação das normas prescritas legalmente e a sua real aplicação. Riggs (1964, p.123) considera que o formalismo corresponderia:

[...] ao grau de discrepância entre o prescritivo e o descritivo, entre o poder formal e o poder efetivo, entre a impressão que nos é dada pela Constituição, pelas leis e regulamentos, organogramas e estatísticas, e os fatos e práticas reais do governo e da sociedade. Quanto maior a discrepância entre o formal e o efetivo, mais formalístico o sistema. 
Através do formalismo as organizações transmitem a impessoalidade às suas ações. Assim pode-se "negar, vetar e conseguir" e o jeitinho faria a ligação das normas impessoais das organizações com um sistema herdado de "relações pessoais que permitem tornar as mesmas leis casuísticas e flexíveis". (BARBOSA, COSTA e VIEIRA, 1996, p.28) O “jeitinho" seria a maneira cordial de convívio do indivíduo com o formalismo. Em um extremo estariam os dominadores fazendo uso das leis para seu benefício próprio ou de seus protegidos, e no outro, os dominados utilizando-se da cordialidade dos fortes para escaparem dos rigores legais. Os autores citam Guerreiro Ramos (1996, p.19) para apresentar o formalismo como estratégia ideológica para dirimir tensões sociais, pois "quando as leis não se cumprem é porque não o querem os poderosos". Nesse sentido poder-se-ia considerar a cordialidade como uma maneira de amenizar os rigores da lei quando há conveniência para o poder concedente. Se a lei é para todos, então porque não se observa igual aplicabilidade delas? Vale o ditado popular: "Aos amigos, tudo; aos indiferentes, nada; aos inimigos a lei." Seria dizer que mesmo a lei pode apresentar-se cordial para os amigos.

\subsection{Cordialidade X Civilidade}

Para Weber (1963, p.251), formalismo e burocracia se associam. Segundo ele, a burocracia se desumaniza à medida que a sociedade evolui. Quanto mais desenvolvida a sociedade, mais mecanicista se torna, afastando-se, portanto, dos valores emocionais. A essa desumanização da sociedade, Weber (1963) utiliza o conceito de civilidade para descrever o processo de racionalização e impessoalização das relações humanas. A cordialidade se contrapõe à civilidade, pois ela representa as relações humanas mais afetivas.

Richard Sennet (ap. AVELINO, 1990) dizia que a civilidade faz movimentar o mundo no meio urbano. Ela concebe ao indivíduo "máscaras" que garantem distâncias necessárias para seu convívio no novo mundo. Seria uma forma das pessoas se relacionarem sem se conhecerem intimamente, desempenhando papéis que a sociedade lhes atribui. Alivia-se assim uma carga emocional do seu "próprio eu" de forma a poderem ter contato com desconhecidos e ter uma vida social prazerosa. Nasceria dessa transformação o homem civilizado.

A contenção dos impulsos pessoais leva à criação de formas artificiais de sociabilidade, reconhecida por todos, e à capacitação do indivíduo em lidar com seu exterior de forma mais neutra do ponto de vista afetivo. Assim, forja-se o indivíduo civilizado, capaz de determinar de forma independente seus interesses e constituidor de um espaço público. (AVELINO, 1990, p.10) 
O homem cordial daria espaço ao homem civilizado, à medida que o processo de urbanização e industrialização ocorresse, segundo Holanda (1995). A herança colonial rural e patriarcal, marcada pelo personalismo iria gradativamente cedendo espaço à civilidade. A cidade dominaria o campo e não mais o contrário. O Estado passaria a se impor aos poucos através de um conjunto de regras mais universais e impessoais ao invés de personalistas e patrimonialistas. A razão deveria prevalecer ao sentimento na evolução urbana e com isso nossas raízes ibéricas seriam resquícios do passado, assim como desapareceria a cordialidade nas relações sociais. A civilidade seria condição de desenvolvimento social e seria uma conseqüência da relação urbanização/industrialização como expressa Avelino (1990, p.9):

O indivíduo civilizado é fruto do processo de urbanização e industrialização pelos quais passaram as culturas européias. A civilidade seria composta por um conjunto de relações artificiais e padronizadas, em oposição às relações familiares baseadas no afeto e no sangue, existem as exigências imperativas das novas condições de vida - um processo pelo qual "a lei geral suplanta a lei particular" - que se manifestam na urbanização e na industrialização.

$\mathrm{Na}$ sociedade brasileira a civilidade encobre os traços da herança cordial e uma de suas manifestações está no "jeitinho brasileiro" e na hospitalidade que encanta os estrangeiros. A questão da hospitalidade brasileira é histórica e está registrada em diversas passagens que, segundo Pires (2002), mostram a admiração de estrangeiros pela receptividade brasileira já no século XIX. Pires aponta para interesses diversos para dar acolhida aos viajantes, como o de manter intimidade com autoridades de forma a conseguir favores materiais ou políticos, cujos objetivos estariam associados à cordialidade mencionada por Holanda. Quanto aos viajantes estrangeiros, havia orgulho em recebê-los por tratar-se de pessoas ligadas às ciências, às artes, de notório conhecimento, ou "simplesmente estrangeiros". O fascínio de brasileiros por estrangeiros poderia ser explicado também pela histórica dependência econômico-financeira de um país periférico em relação aos países centrais, pois se produzia no Brasil principalmente para atender o mercado externo. Essa admiração pela hospitalidade brasileira está bem retratada neste depoimento de Burton: (ap. PIRES, 2002, p. 133)

[...] coisa estranha: em Londres, em meio de três milhões de homens, Chateaubriand proscrito teve fome. Neste país, deserto, imenso, num canto desses bosques, humilde viajante, podeis entrar. A fazenda se abrirá para o pão e para o teto. Onde estão os verdadeiros civilizados? 
$\mathrm{O}$ resultado da pesquisa encomendada pela EMBRATUR/ à FIPE mostra que não foram as belezas naturais, a cultura, o clima ou a curiosidade pelo país os fatores que mais atraíram os turistas pesquisados, mas sim a "hospitalidade/gosto pelo Brasil".

Segundo Beni (2001, p.37), a atividade turística depende basicamente dos atrativos turísticos (naturais e culturais) e da qualidade dos serviços prestados pelo setor e oferecidos ao mercado. Para esse autor, turismo pode ser definido como:

[...] um elaborado e complexo processo de decisão sobre o que visitar, onde, como e a que preço. Nesse processo intervêm inúmeros fatores de realização social e pessoal, de natureza motivacional, econômica, cultural, ecológica e científica que ditam a escolha dos destinos, a permanência, os meios de transporte e o alojamento, bem como o objetivo da viagem em si para a fruição tanto material como subjetiva dos conteúdos de sonhos, desejos, de imaginação projetiva, de enriquecimento existencial histórico - humanístico, profissional, e de expansão de negócios.

Quanto ao entendimento de atrativo turístico Beni (2001) afirma ser todo lugar, objeto ou acontecimento de interesse turístico que motiva o deslocamento de grupos humanos para conhecê-los e que "atrativos turísticos é outro nome para recursos turísticos, que constituem o patrimônio turístico". São estes recursos, considerados os principais elementos passíveis de provocar deslocamentos de pessoas, e que por sua vez integram o "marco geográficoecológico-cultural" de um lugar.

É importante, pois, compreender a dinâmica do mercado turístico para que as potencialidades da cultura hospitaleira/cordial do brasileiro possam agregar valor ao produto turístico nacional. A expressão "gosto pelo Brasil" reforça a idéia de hospitalidade, a faz mais sentimental e, porque não dizer?, mais cordial na acepção de Holanda. Como este aspecto subjetivo cedeu lugar à civilidade nos países desenvolvidos, os povos mais civilizados reencontrariam no Brasil o calor das relações afetivas perdidas. Relações essas que aquecem os corações e aproximam as pessoas.

\section{Considerações Finais}

As tradições e cultura de um povo representam o conjunto de valores que conferem uma identidade social a uma nação. Wright, Kroll e Parnell (2000) as consideram forças sociais do macroambiente. Segundo eles, as tradições afetam práticas sociais que duram por, até mesmo, séculos. O Natal no Ocidente seria um exemplo de tradição que oferece oportunidades de 
vendas para o comércio e a indústria. São esses valores que uma sociedade tem em alta conta para si mesma. Como, por exemplo, a liberdade do indivíduo e igualdade de oportunidades nos EUA, que atraíram milhões de imigrantes àquele país, em busca de prosperidade.

Por outro lado, Porter (1991) diz que a competitividade de uma nação depende da capacidade da sua indústria em inovar e evoluir. Vantagens competitivas são criadas e sustentadas através de processos locais. As diferenças de valores nacionais, culturais, institucionais e históricos são todos contribuintes para o sucesso de sua competitividade e são muito diferentes de país para país. Nenhuma nação pode ser competitiva em todas as indústrias ou mesmo na maioria delas. Ultimamente, nações têm sido exitosas em algumas indústrias em particular, porque encontram no seu ambiente interno condições propícias para se desenvolverem.

Dessa forma, seria então a característica de hospitalidade/cordialidade, como revela a pesquisa da FIPE/EMBRATUR, o diferencial explicativo do encantamento dos estrangeiros em viagem ao Brasil? Se afirmativa, a resposta a esta questão, encontraríamos no próprio povo brasileiro (o 'homem cordial' de Holanda) e no seu habitat (o Brasil) a grande vantagem competitiva da indústria do turismo brasileiro na competição internacional.

\section{Referências}

ALCADIPANI, Rafael; MOTTA, Fernando C. Prestes. 1999. Jeitinho brasileiro, controle social e competição. In: Revista de Administração de Empresas. São Paulo, v.39, n.1.

AVELINO FILHO, George. 1990. Cordialidade e civilidade em raízes do Brasil. In: Revista Brasileira de Ciências Sociais. $\mathrm{n}^{\mathrm{o}}$ 12. São Paulo.

BARROS, Betânia; PRATES, Marco Aurélio S.; DINIZ, Ulisses F. 1991. A arte brasileira de administrar. Fundação Dom Cabra. CTE - INSEAD. Belo Horizonte.

BARBOSA, Oliveira Lázaro; COSTA, Frederico Lustosa da; VIEIRA, Clóvis Abreu. 1982. O "jeitinho" brasileiro como recurso de poder. In: Revista de Administração Pública. Rio de Janeiro, v.2.

BENI, Mário Carlos. 2001. Análise estrutural do turismo. 4 ed. São Paulo: Editora SENAC.

ESTEVES, Paulo Luiz Moreaux Lavigne. 1998. Cordialidade e familismo amoral: os dilemas da modernização. Revista Brasileira de Ciências Sociais. v. 13 n. 36. São Paulo, Fev.

FREYRE, Gilberto. 2005. Casa Grande \& Senzala: formação da família brasileira sob o regime de economia patriarcal. Rio de Janeiro: Global.

HOLANDA, Sérgio Buarque de. 1995. Raizes do Brasil. 26 ed. São Paulo: Companhia das Letras.

I COLÓQUIO SOBRE CULTURA BRASILEIRA DA HOSPITALIDADE. In: Movimento Brasil de Turismo e Cultura. Disponível em: <http:www.movimentobrasil.org.br>. Acesso em: nov 2006.

MINISTÉRIO DO TURISMO. 2006. Estatística básica do turismo no Brasil. Ministério do Turismo. Brasília. Disponível em: <http:www.institucional.turismo.gov.br/dadosefatos/estatísticas eindicadores>. Acesso em 10 abr 2007.

PIRES, Mário Jorge. 2002. Raízes do turismo no Brasil. 2 ed. Barueri-SP: Editora Manole. 
PORTER, E. Michael. 1991. The Competitive Advantage of Nations. In: Stategy: seeking and securing competitive advantage. MONTGOMERY, A. Cynthia, PORTER, E. Michael. Boston, USA: Harvard Business School Publishing Division.

REIS, José Carlos. 2005. As identidades do Brasil: de Varnhagem a FHC. 7 ed. Rio de Janeiro: Editora FGV.

RIGGS, F. W. 1964. The Ecology of Public Administration. New York: Asia Publishing House.

WALTER, Praxedes. s/d. Reflexões sociológicas sobre hospitalidade. In: Revista Espaço Acadêmico. n. 37 .Disponível em: <http: www.espacoacademico.com.br>. Acesso em: out 2004.

WEBER, Max. 1963. Ensaios de Sociologia. GERTH, H.H. e MILLS C. Wright. Rio de Janeiro: Editora Hahar.

WORLD TOURISM ORGANIZATION. s/d. Tourism and world economy. Disponível em: $<$ http:www.world-tourism.org/facts \& figures>. Acesso em 12 abr 2007.

. s/d. Tourism 2020 vision. Disponível em <http:www.world-tourism.org/facts \& figures>. Acesso em 12 abr 2007. s/d. Tourism indicators. Disponível em <http:www.world-tourism.org/facts \& figures $>$. Acesso em 12 abr 2007.

WRIGHT, Peter; KROLL, J. Mark; PARNELL, John. 2000. Administração estratégica: conceitos. 4 ed. São Paulo.

Recebido em: 14/07/2008 (1 $1^{\text {a }}$ versão) $17 / 08 / 2008$ ( $2^{\text {a }}$ versão)

Aprovado em: 11/06/2009 